\title{
A Case of Fissure-Like Pressure Ulcer on the Coccygeal Area Successfully Treated with Changing of Wound Dressing
}

\author{
Shigeki Inui* and Satoshi Itami
}

Department of Regenerative Dermatology, Osaka University School of Medicine, 2-2, G2, Yamadaoka, Suita-shi, Osaka, 565-0871, Japan

\begin{abstract}
A 61-year-old Japanese woman developed pressure ulcer on her sacral and coccygeal area due to a long-term bed rest. After she received the treatment by bucladesine sodium ointment, trafermin (recombinant human basic FGF) splay and TIELLE ${ }^{\circledR}$ (Johnson \& Johnson Co) hydropolymer dressing, the ulcer gradually reduced in size and depth. However, the improvement of the fissure-like ulcer decelerated when the size became around $2 \mathrm{X} 2 \mathrm{~cm}$. Thereafter the occlusion by hydrocolloid dressing was continued for around two years with only slight effect, decreasing the size to around $1 \mathrm{X} 1 \mathrm{~cm}$. Finally, we changed the dressing to the hydropolymer dressing TIELLE ${ }^{\circledR}$ plus, which can absorb superfluous oozing well, because maceration was found on the perilesional skin. Then, the ulcer was rapidly healed and epithelized in two weeks, suggesting that the excess secretion had delayed of wound healing.
\end{abstract}

\section{CASE PRESENTATION}

A 61-year-old Japanese woman had suffered from intracranial hemorrhage and its aftereffect and developed pressure ulcer on her sacral and coccygeal area due to a long-term bed rest (Fig. 1a). After she received the treatment by bucladesine sodium ointment, trafermin (recombinant human basic FGF) splay and TIELLE ${ }^{\circledR}$ (Johnson \& Johnson Co) hydropolymer dressing, the ulcer gradually reduced in size and depth. However, the improvement of the fissure-like ulcer decelerated when the size became around $2 \mathrm{X} 2 \mathrm{~cm}$. Thereafter the occlusion by hydrocolloid dressing was continued for around two years with only slight effect, decreasing the size to around $1 X 1 \mathrm{~cm}$, while the granulation tissue was well colored (Fig. 1b). Finally, we changed the dressing to the hydropolymer dressing TIELLE $^{\circledR}$ plus (Johnson \& Johnson Co), which can absorb superfluous oozing well [1, 2], because maceration was found on the perilesional skin (Fig. 1b). Then, the ulcer was rapidly healed and epithelized in two weeks (Fig. 1c), suggesting that the excess secretion had delayed of wound healing.

\section{COMMENTS}

Pressure ulcer is tissue damage caused by excess pressure, shearing or friction forces on the bony of the malnourished patients or those with acute illness. The treatments include reducing pressure, friction and shear forces, removing necrotic debris, managing bacterial contamination, and correcting nutritional deficits. Moreover, for optimizing local wound care, drugs and dressings should be appropriately chosen, depending on the state of pressure ulcers.

Initially basic FGF and hydrocolloid dressing were effective for our case, reducing the size and depth. Indeed, the efficacy of basic FGF is well evidenced by the randomized,

*Address correspondence to this author at the Sudbury Department of Regenerative Dermatology, Osaka University School of Medicine, 2-2, G2, Yamadaoka, Suita-shi, Osaka, 565-0871, Japan; Tel: 81-6-6879-3960; Fax: 81-6-6879-3962; E-mail: inui@r-derma.med.osaka-u.ac.jp

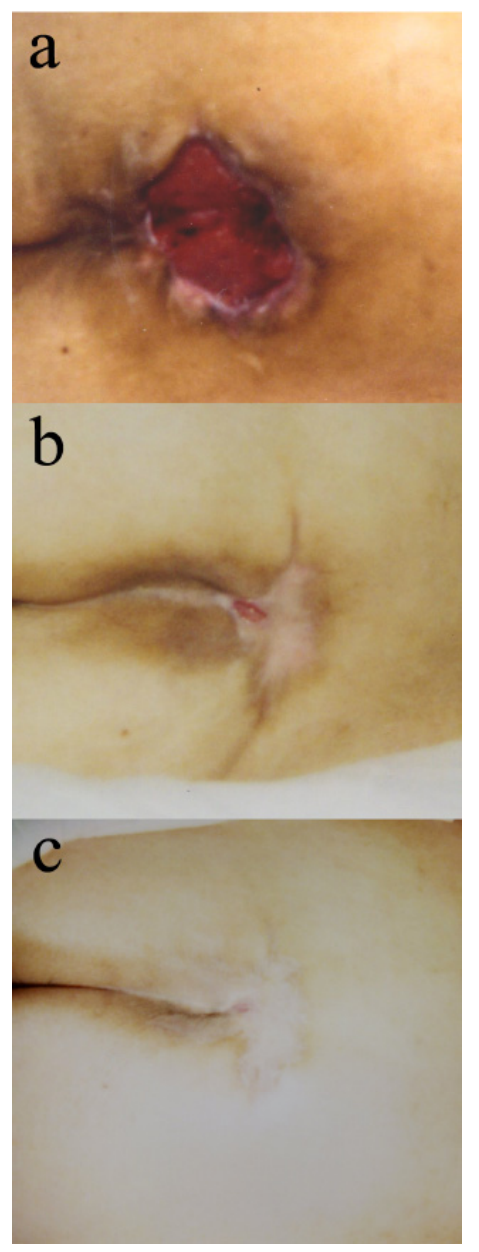

Fig. (1). Clinical appearance of the skin ulcer. (a) When the patient was hospitalized, the pressure ulcer was found. (b) The occlusion by hydrocolloid dressing was continued for around two years with only slight effect, decreasing the size to around $1 X 1 \mathrm{~cm}$. (c) The ulcer was rapidly healed and epithelized in two weeks after TIELLE $^{\mathbb{R}}$ plus dressing was started. 
blinded, placebo-controlled human trial for pressure ulcer. In this trial 21 of $35(60 \%)$ patients receiving bFGF achieved a $70 \%$ volume reduction although four of $14(28.6 \%)$ patients in the placebo group achieved it. This outcome is significantly different by the Fisher's exact test $(p=0.047)$ [3]. On the other hand the recent systematic literature review demonstrated that hydrocolloid dressings are more effective than gauze dressings for the reduction of the wound dimensions of the pressure ulcer [4]. Therefore, the combined application of bFGF and hydrocolloid seems reasonable. However, recently the controlled delivery of bFGF using gelatin hydrogel has been reported [5] and thus the improvement of dressings may be needed to enhance the effect of bFGF for the clinical practice of pressure ulcer.

The choice of dressing may be significant for our case in the following two points. First, because the change of dressing to hydropolymer TIELLE $^{\circledR}$ plus rapidly improved the pressure ulcer with maceration, hydropolymer dressing is more hygroscopic than hydrocolloid dressing. It was previously reported that hydropolymer dressing is more beneficial than hydrocolloid in terms of controlling the exudate production [6]. Second, because the shape of the fissure-like ulcer seen in our case suggests that shear stress plays an important role to cause the ulcer and moreover hydrocolloid dressing was reported to be tightly adherent to skin [7], we assume that its adhesiveness augmented the shear stress to the perilesional skin.

\section{REFERENCES}

[1] Schulze HJ. Clinical evaluation of TIELLE plus dressing in the management of exuding chronic wounds. Br J Community Nurs 2003; 8: 18-22.

[2] Norkus A, Dargis V, Thomsen JK, et al. Use of a hydrocapillary dressing in the management of highly exuding ulcers: A comparative study. J Wound Care 2005; 14: 429-32.

[3] Robson MC, Phillips LG, Lawrence WT, et al. The safety and effect of topically applied recombinant basic fibroblast growth factor on the healing of chronic pressure sores. Ann Surg 1992; 216: 401-6.

[4] Heyneman A, Beele H, Vanderwee K, Defloor T. A systematic review of the use of hydrocolloids in the treatment of pressure ulcers. J Clin Nurs 2008; 17: 1164-73.

[5] Fujihara Y, Koyama H, Ohba M, et al. Controlled delivery of bFGF to recipient bed enhances the vascularization and viability of an ischemic skin flap. Wound Repair Regen 2008; 16: 125-31.

[6] Thomas S, Banks V, Bale S, et al. A comparison of two dressings in the management of chronic wounds. J Wound Care 1997; 6: 3836.

[7] Ohura N, Ichioka S, Nakatsuka T, Shibata M. Evaluating dressing materials for the prevention of shear force in the treatment of pressure ulcers. J Wound Care 2005; 14: 401-4. 